Quim. Nova, Vol. 35, No. 8, 1612-1618, 2012

\title{
COMPOSIÇÃO QUÍMICA DE AGUARDENTES DE CANA-DE-AÇÚCAR FERMENTADAS POR DIFERENTES CEPAS DE LEVEDURA Saccharomyces cerevisiae
}

\author{
André Ricardo Alcarde*, Bruno Miguel dos Santos Monteiro e André Eduardo de Souza Belluco \\ Departamento de Agroindústria, Alimentos e Nutrição, Escola Superior de Agricultura Luiz de Queiroz, Universidade de São \\ Paulo, CP 9, 13418-900 Piracicaba - SP, Brasil
}

Recebido em 16/2/12; aceito em 11/4/12; publicado na web em 20/7/2012

\begin{abstract}
CHEMICAL COMPOSITION OF SUGAR CANE SPIRITS FERMENTED BY DIFFERENT Saccharomyces cerevisiae YEAST STRAINS. The aim of this study was to evaluate the chemical composition of sugar cane spirits, fermented by different commercial Saccharomyces cerevisiae yeast strains and double distilled by pot still. Sugar cane juices were separately fermented by yeasts CA-11, Y-904, BG-1, PE-2, SA-1 and CAT-1 and distilled by pot still according to the methodology used for whisky production. The alcoholic liquids from first and second distillations were analyzed for concentrations of ethanol, volatile acidity, aldehydes, esters, furfural, higher alcohols and methanol. The sugar cane spirits derived from fermentation by the different yeast strains presented distinct chemical compositions.
\end{abstract}

Keywords: yeast; cachaça; chemical composition.

\section{INTRODUÇÃO}

O Brasil vem se destacando na produção de cachaça, sendo a segunda bebida alcoólica mais consumida do país e a primeira entre as bebidas destiladas nacionais. ${ }^{1}$ A produção anual atinge 2 bilhões de litros, representando uma atividade econômica estimada de US\$ 2,5 bilhões. $^{2}$ Em relação à Legislação Brasileira (Instrução Normativa $n^{\circ} 13$ de 29/06/2005) a denominação aguardente de cana-de-açúcar se refere à bebida com graduação alcoólica de 38 a 54\% em volume, a $20{ }^{\circ} \mathrm{C}$, obtida pela destilação do mosto fermentado do caldo de cana-de-açúcar (Saccharum officinarum), podendo ser adicionada de até $6 \mathrm{~g} \mathrm{~L}^{-1}$ de açúcares. A cachaça se refere à denominação típica e exclusiva da aguardente de cana-de-açúcar produzida no Brasil, com graduação alcoólica de 38 a $48 \%$ em volume, a $20{ }^{\circ} \mathrm{C} .{ }^{3}$ Os padrões de identidade e qualidade da aguardente de cana-de-açúcar brasileira também são estabelecidos por esta legislação (Tabela 1). ${ }^{3}$

A aguardente de qualidade, isto é, aquela que apresenta

Tabela 1. Padrões de identidade e qualidade de aguardente de cana-de-açúcar, segundo a legislação nacional vigente ${ }^{3}$

\begin{tabular}{|c|c|}
\hline Compostos & Limites \\
\hline Grau alcoólico & 38 a $54 \% \mathrm{v} \mathrm{v}^{-1}$ a $20^{\circ} \mathrm{C}$ \\
\hline Acidez volátil (em ácido acético) & Máximo 0,150 g $100 \mathrm{~mL}^{-1}$ (álcool anidro) \\
\hline Ésteres (em acetato de etila) & Máximo 0,200 g $100 \mathrm{~mL}^{-1}$ (álcool anidro) \\
\hline Aldeídos (em aldeído acético) & Máximo 0,030 g $100 \mathrm{~mL}^{-1}$ (álcool anidro) \\
\hline Furfural & Máximo 0,005 g $100 \mathrm{~mL}^{-1}$ (álcool anidro) \\
\hline $\begin{array}{l}\text { Alcoóis superiores (soma de pro- } \\
\text { panol, iso-butanol e iso-amílico) }\end{array}$ & Máximo 0,360 g $100 \mathrm{~mL}^{-1}$ (álcool anidro) \\
\hline $\begin{array}{l}\text { Coeficiente de congêneres (Soma } \\
\text { de acidez volátil, ésteres, aldeídos, } \\
\text { furfural e alcoóis superiores) }\end{array}$ & 0,200 a 0,650 g $100 \mathrm{~mL}^{-1}$ (álcool anidro) \\
\hline Metanol & Máximo 0,020 g $100 \mathrm{~mL}^{-1}$ (álcool anidro) \\
\hline Cobre & Máximo 5 mg L-1 \\
\hline Carbamato de etila & Máximo $0,150 \mathrm{mg} \mathrm{L}^{-1}$ \\
\hline
\end{tabular}

*e-mail: andre.alcarde@usp.br composição química adequada e características sensoriais superiores, vem tendo o seu nicho de mercado, principalmente entre a população de maior poder aquisitivo, a qual procura uma bebida destilada diferenciada. $\mathrm{O}$ aumento do consumo de aguardente e a possibilidade de exportação exigem que o processo de fabricação seja baseado em práticas criteriosamente determinadas, para obtenção de um produto padronizado e com qualidade comprovada nos aspectos físico-químicos e sensoriais. ${ }^{4,5}$ Como o mercado de consumo de bebidas destiladas, interno e externo, torna-se cada vez mais exigente, é importante a determinação dos compostos químicos da bebida, que estão intimamente relacionados com o aroma e o sabor do destilado. ${ }^{6}$

Diversos fatores influenciam a qualidade da cachaça, tais como a qualidade da matéria-prima, as condições de fermentação e os processos de destilação e envelhecimento. No entanto, as leveduras e as condições da fermentação são os fatores que mais afetam as qualidades química e sensorial da cachaça. A fermentação do caldo de cana pode ser considerada espontânea, pois normalmente não se utilizam cepas de leveduras selecionadas como inóculo. Desta forma, se caracteriza uma grande diversidade de espécies de microrganismos, com predominância de leveduras, especialmente a Saccharomyces cerevisiae. Ainda, o processo fermentativo é realizado em reciclos sucessivos do fermento. Como consequência, a composição química da cachaça é muito variável ao longo do período de produção, que normalmente se realiza entre maio e novembro. ${ }^{7}$

Alcoóis superiores, ésteres, aldeídos e ácidos orgânicos são os compostos responsáveis pelo aroma e sabor típicos de bebidas e desempenham um importante papel na formação do perfil sensorial de destilados. ${ }^{8}$

Os componentes químicos da aguardente são oriundos, principalmente, das reações metabólicas envolvidas na bioquímica da fermentação alcoólica. As condições físico-químicas e as características microbiológicas do processo de fermentação influenciam a produção dos compostos químicos da bebida. Segundo Janzantti, a quantidade de alcoóis superiores em aguardentes é influenciada pela composição do meio, temperatura, nível de aeração e, também, pela linhagem da levedura, sendo a síntese de alcoóis superiores estimulada pelo oxigênio e estando diretamente relacionada com a taxa de crescimento da levedura. ${ }^{9,10}$ Giudici et al. ${ }^{11}$ estudaram a capacidade de produção de alcoóis superiores em 100 linhagens de leveduras Saccharomyces 
cerevisiae e encontraram diferenças estatisticamente significativas, concluindo que a potencialidade de produção de alcoóis superiores é uma característica inerente de cada linhagem de levedura.

Em muitos casos o processo fermentativo para produção de aguardente ainda é empírico, utilizando leveduras selvagens, isto é, aquelas trazidas do campo com a própria cana. A ocorrência de diferentes espécies e linhagens de leveduras pode interferir negativamente na qualidade do produto final. A utilização deste tipo de inóculo proporciona fermentações totalmente aleatórias, pois depende da quantidade e da qualidade dos microrganismos presentes no caldo. Têm sido realizadas pesquisas no sentido de isolar e selecionar leveduras com características favoráveis para realizar o processo fermentativo para produção de etanol combustível e, também, para a produção de aguardente. ${ }^{12,-14} \mathrm{~A}$ utilização de leveduras selecionadas na produção de cachaça acelera o início do processo fermentativo, diminui o risco de contaminação microbiológica, reduz a concentração de açúcares residuais, aumenta a produtividade do processo e melhora a padronização da fermentação, contribuindo para a qualidade da bebida, principalmente em relação aos teores de acidez e concentração de alcoóis superiores, produzindo aguardente com características sensoriais adequadas. ${ }^{15-17}$

Este trabalho teve como objetivo comparar a composição química de aguardentes de cana-de-açúcar fermentadas por diferentes cepas comerciais da levedura Saccharomyces cerevisiae.

\section{PARTE EXPERIMENTAL}

Os mostos foram obtidos a partir de caldo de cana-de-açúcar, da variedade SP83-2847, extraídos em moenda, filtrados em algodão e levados à ebulição por 10 min para estabilização microbiológica e química. Em seguida, foram novamente filtrados e padronizados a 18 obrix, através de diluição com água destilada. Os fermentos utilizados foram leveduras Saccharomyces cerevisiae, cepas Y-904 (AB Brasil, Pederneiras-SP, Brasil), CA-11, BG-1, PE-2, SA-1 ou CAT-1 (LNF - Latino Americana, Bento Gonçalves-RS, Brasil).

As fermentações foram conduzidas em dornas de aço inoxidável de $50 \mathrm{~L}$ de capacidade útil. A temperatura das fermentações foi controlada entre 28 e $30^{\circ} \mathrm{C}$, através de sistema interno (camisa) de resfriamento e/ou aquecimento acoplado a um banho termostatizado. As fermentações, em sistema de batelada, foram inoculadas com 3 $\mathrm{g} \mathrm{L}^{-1}$ do fermento seco.

As destilações dos vinhos foram realizadas em alambique simples, com caldeira, capitel e alonga de cobre e condensador de aço inoxidável. O alambique é equipado com termômetro e com sistema de aquecimento a gás, o que proporciona um processo de destilação mais padronizado do ponto de vista de velocidade de aquecimento e de temperatura e pressão dos vapores formados. A caldeira do alambique possui capacidade útil de $37 \mathrm{~L}$ de vinho.

Foi empregada a técnica da dupla destilação, baseada na metodologia utilizada para a produção de whisky. ${ }^{18} \mathrm{Na}$ primeira destilação, a do vinho, procedeu-se à recuperação de praticamente todo o álcool, isto é, até que o destilado na saída do condensador apresentasse 5\% (v/v), medido em alcoômetro. Não houve separações de fração do destilado na primeira destilação. A primeira destilação produziu um destilado que foi chamado de low wines. Foram necessárias três bateladas de primeiras destilações para a produção de um volume suficiente de low wines para a segunda destilação.

Na segunda destilação, a do low wines, o destilado foi dividido em três frações. A primeira fração recolhida, denominada "cabeça", correspondeu a $2 \%$ do volume de low wines. A segunda fração, o "coração" ou a aguardente propriamente dita, foi o destilado recolhido após a fração "cabeça" e até que a graduação alcoólica do líquido na saída do condensador fosse de $60 \%$ (v/v). A terceira e última fração, a "cauda", foi a que correspondeu ao destilado recolhido após a fração aguardente e até a graduação alcoólica de 5\% (v/v) do líquido, medidos na sua saída do condensador.

O low wines e as frações "cabeça", "coração" e "cauda" do destilado final foram analisados seguindo as metodologias oficiais, quanto à concentração alcoólica, acidez volátil (em ácido acético), aldeídos (em aldeído acético), ésteres (em acetato de etila), furfural, álcool n-propílico, álcool iso-butílico, álcool iso-amílico e metanol. ${ }^{19}$

As análises de aldeídos, ésteres, metanol e alcoóis superiores (n-propanol, iso-butanol e álcool iso-amílico) foram realizadas utilizando um cromatógrafo gasoso CG-037, equipado com uma coluna empacotada PAAC 3334-CG e um detector de ionização de chama (FID). Como gás de arraste utilizou-se $\mathrm{H}_{2}$, com vazão de 30 $\mathrm{mL} \mathrm{min}{ }^{-1}$. As temperaturas do injetor e detector foram programadas para 170 e $225^{\circ} \mathrm{C}$, respectivamente. A programação da temperatura da coluna foi isotérmica a $94{ }^{\circ} \mathrm{C} .{ }^{20} \mathrm{~A}$ quantificação dos compostos

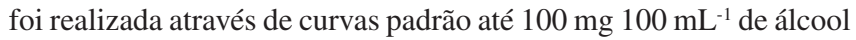
anidro (AA) para aldeídos, ésteres e n-propanol, até $30 \mathrm{mg}^{100 \mathrm{~mL}^{-1}}$ de AA para metanol, até $250 \mathrm{mg} 100 \mathrm{~mL}^{-1}$ de AA para iso-butanol e até $500 \mathrm{mg} 100 \mathrm{~mL}^{-1}$ de AA para álcool iso-amílico.

Todos os reagentes foram de grau analítico, adquiridos da Merck (Darmstadt, Germany). Para as diluições foram utilizados etanol de grau analítico para cromatografia (Merck, Darmstadt, Germany) e água ultrapura (Milli-Q).

A análise estatística dos resultados foi realizada através da aplicação do teste F ao nível de 5\% de significância e do teste de Tukey, através do programa estatístico SAS, dentro de um delineamento experimental inteiramente casualisado, com 3 repetições. ${ }^{21,22}$

\section{RESULTADOS E DISCUSSÃO}

\section{Low wines}

O teor alcoólico médio dos destilados finais das primeiras destilações (low wines) foi de 32,1\% (v/v) (Tabela 2).

O low wines obtido da destilação do mosto fermentado pela levedura BG-1 apresentou a maior acidez volátil (241,94 mg 100 $\mathrm{mL}^{-1}$ de AA). A levedura SA-1 produziu o destilado de menor acidez volátil (124,16 mg $100 \mathrm{~mL}^{-1}$ de AA).

O low wines da levedura CA-11 apresentou a maior concentração de aldeídos (22,01 mg $100 \mathrm{~mL}^{-1}$ de AA), não havendo diferença em relação à levedura CAT-1, cuja concentração deste componente foi de 21,46 mg $100 \mathrm{~mL}^{-1}$ de AA. O destilado da levedura BG-1 apresentou a menor concentração de aldeídos $\left(9,49 \mathrm{mg} 100 \mathrm{~mL}^{-1} \mathrm{de} \mathrm{AA}\right)$.

A maior concentração de ésteres $\left(28,72 \mathrm{mg} 100 \mathrm{~mL}^{-1}\right.$ de AA) foi observada no low wines da levedura SA-1. As leveduras CA-11, BG-1, PE-2 e CAT-1 foram as que produziram destilados com as menores concentrações deste composto, $15 \mathrm{mg} 100 \mathrm{~mL}^{-1}$ de AA.

A concentração de furfural dos destilados das diferentes leveduras variou de 0,09 a $0,19 \mathrm{mg} 100 \mathrm{~mL}^{-1}$ de AA.

A levedura SA-1 foi a que originou low wines com os maiores teores de n-propanol e de iso-butanol, 39,07 e 168,87 mg $100 \mathrm{~mL}^{-1}$ de AA, respectivamente. Os destilados das leveduras CA-11, Y-904 e BG-1 apresentaram as menores concentrações de n-propanol, na

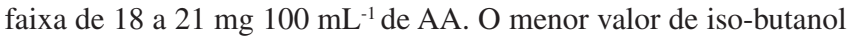
foi observado no tratamento com a levedura CA-11 (27,81 mg 100 $\mathrm{mL}^{-1}$ de AA).

As leveduras Y-904 e SA-1 foram as que originaram destilados com as maiores concentrações de álcool iso-amílico, 308,88 e 323,65 mg $100 \mathrm{~mL}^{-1}$ de AA, respectivamente. O menor teor deste componente foi observado no low wines proveniente da destilação do mosto fermentado pela levedura BG-1, o qual apresentou também o menor valor de alcoóis superiores (131,99 mg $\left.100 \mathrm{~mL}^{-1} \mathrm{de} \mathrm{AA}\right)$, não diferindo 
Tabela 2. Composição química do destilado da primeira destilação (low wines) dos mostos fermentados com as diferentes leveduras

\begin{tabular}{|c|c|c|c|c|c|c|}
\hline & CA-11 & Y-904 & BG-1 & PE-2 & SA-1 & CAT-1 \\
\hline Teor alcoólico $\left(\% \mathrm{v} \mathrm{v}^{-1} 20^{\circ} \mathrm{C}\right)$ & $31,26^{\mathrm{a}}$ & $33,13^{\mathrm{a}}$ & $30,75^{\mathrm{a}}$ & $32,51^{\mathrm{a}}$ & $32,27^{\mathrm{a}}$ & $32,71^{\mathrm{a}}$ \\
\hline Acidez volátil* & $183,98^{\mathrm{b}}$ & $147,61^{\mathrm{c}}$ & $241,94^{\mathrm{a}}$ & $157,89^{\mathrm{c}}$ & $124,16^{\mathrm{d}}$ & $197,01^{\mathrm{b}}$ \\
\hline Aldeídos* & $22,01^{\mathrm{a}}$ & $17,56^{\mathrm{b}}$ & $9,49^{\mathrm{c}}$ & $18,51^{\mathrm{b}}$ & $18,22^{\mathrm{b}}$ & $21,46^{\mathrm{a}}$ \\
\hline Ésteres* & $15,65^{\mathrm{c}}$ & $23,74^{\mathrm{b}}$ & $15,65^{\mathrm{c}}$ & $15,71^{\mathrm{c}}$ & $28,72^{\mathrm{a}}$ & $15,79^{\mathrm{c}}$ \\
\hline Furfural* & $0,11^{\mathrm{bc}}$ & $0,19^{\mathrm{a}}$ & $0,15^{\mathrm{ab}}$ & $0,17^{\mathrm{a}}$ & $0,09^{\mathrm{c}}$ & $0,13^{\mathrm{b}}$ \\
\hline Álcool n-propílico* & $19,89^{\mathrm{c}}$ & $21,54^{\mathrm{c}}$ & $18,29^{\mathrm{c}}$ & $39,07^{\mathrm{a}}$ & $30,63^{\mathrm{b}}$ & $33,07^{\mathrm{b}}$ \\
\hline Álcool iso-butílico* & $27,81^{\mathrm{e}}$ & $132,79^{\text {bc }}$ & $48,98^{\mathrm{d}}$ & $168,87^{\mathrm{a}}$ & $146,59^{\mathrm{b}}$ & $123,09^{\circ}$ \\
\hline Álcool iso-amílico* & $112,22^{\mathrm{c}}$ & $308,88^{\mathrm{a}}$ & $64,72^{\mathrm{d}}$ & $207,54^{\mathrm{b}}$ & $323,85^{\mathrm{a}}$ & $211,28^{\mathrm{b}}$ \\
\hline Alcoóis superiores* & $159,91^{\mathrm{d}}$ & $463,22^{\mathrm{a}}$ & $131,99^{\mathrm{d}}$ & $415,48^{\mathrm{b}}$ & $501,07^{\mathrm{a}}$ & $367,44^{\circ}$ \\
\hline Coeficiente de congêneres* & $381,66^{\mathrm{b}}$ & $652,32^{\mathrm{a}}$ & $399,22^{\mathrm{b}}$ & $607,76^{\mathrm{a}}$ & $672,26^{\mathrm{a}}$ & $601,83^{\mathrm{a}}$ \\
\hline Metanol* & $13,64^{\mathrm{b}}$ & $20,95^{\mathrm{a}}$ & $15,89^{\mathrm{b}}$ & $19,99^{\mathrm{a}}$ & $18,31^{\mathrm{a}}$ & $14,64^{\mathrm{b}}$ \\
\hline
\end{tabular}

* mg $100 \mathrm{~mL}^{-1}$ de AA. Letras diferentes nas linhas indicam diferença estatística significativa.

do low wines da levedura CA-11, que apresentou a concentração de $159,91 \mathrm{mg} 100 \mathrm{~mL}^{-1}$ de AA de alcoóis superiores. Os destilados que apresentaram os maiores teores de alcoóis superiores foram os provenientes das leveduras SA-1 e Y-904, 501,07 e 463,22 mg 100 $\mathrm{mL}^{-1}$ de AA, respectivamente.

Os low wines oriundos das leveduras Y-904, PE-2, SA-1 e CAT-1 apresentaram coeficiente de congêneres acima de $600 \mathrm{mg} 100 \mathrm{~mL}^{-1}$ de AA. As leveduras CA-11 e BG-1 produziram destilados com coeficiente de congêneres abaixo de $400 \mathrm{mg} 100 \mathrm{~mL}^{-1}$ de AA.

Os destilados dos mostos fermentados pelas leveduras Y-904, PE-2 e SA-1 apresentaram as maiores concentrações de metanol, variando de 18 a $21 \mathrm{mg} 100 \mathrm{~mL}^{-1}$ de AA. As leveduras CA-11, BG-1 e CAT-1 produziram low wines com os menores valores deste com-

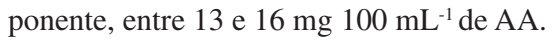

\section{Fração "cabeça"}

O teor alcoólico médio da fração "cabeça" da segunda destilação foi de 77,0\% (v/v) (Tabela 3).

A fração "cabeça" dos destilados provenientes das fermentações com as leveduras CA-11, BG-1 e CAT-1 apresentou as maiores acidez voláteis, variando de 12 a $17 \mathrm{mg} 100 \mathrm{~mL}^{-1}$ de AA. Os destilados das leveduras Y-904, PE-2 e SA-1 apresentaram as menores acidez voláteis, entre 4 e $6 \mathrm{mg} 100 \mathrm{~mL}^{-1}$ de AA.

O destilado da fermentação com a levedura CA-11 apresentou a maior concentração de aldeídos $\left(99,87 \mathrm{mg} 100 \mathrm{~mL}^{-1}\right.$ de AA). As menores concentrações deste componente, entre 48 e $53 \mathrm{mg} 100 \mathrm{~mL}^{-1}$ de AA, foram obtidas das leveduras Y-904, PE-2 e SA-1.

A levedura SA-1 produziu destilado com a maior concentração de ésteres (83,29 mg $100 \mathrm{~mL}^{-1}$ de AA). Os destilados das leveduras CA-11, BG-1 e PE-2 apresentaram as menores concentrações deste composto, na faixa de 49 a $54 \mathrm{mg} 100 \mathrm{~mL}^{-1}$ de AA.

As frações "cabeça" das destilações dos mostos fermentados pelas diferentes leveduras apresentaram concentração de furfural entre 0,01 e $0,04 \mathrm{mg} 100 \mathrm{~mL}^{-1} \mathrm{de}$ AA.

$\mathrm{O}$ destilado da levedura PE-2 apresentou as maiores concentrações de n-propanol e de iso-butanol, 60,63 e 250,46 mg $100 \mathrm{~mL}^{-1}$ de AA, respectivamente. As menores concentrações destes alcoóis superiores foram observadas no destilado da levedura CA-11, 15,72 e 46,41 mg $100 \mathrm{~mL}^{-1}$ de AA, respectivamente.

O destilado da levedura Y-904 apresentou a maior concentração de álcool iso-amílico (422,65 mg $100 \mathrm{~mL}^{-1}$ de AA), não apresentando diferença em relação à levedura SA-1, que apresentou fração "cabeça" com concentração deste composto de 373,95 mg $100 \mathrm{~mL}^{-1}$ de AA. As menores concentrações de álcool iso-amílico foram observadas nos destilados das leveduras CA-11 e BG-1, que foram 161,66 e 125,14 mg $100 \mathrm{~mL}^{-1}$ de AA, respectivamente.

As leveduras Y-904, PE-2 e SA-1 originaram destilados com as maiores concentrações de alcoóis superiores, entre 591 e 648 mg 100 $\mathrm{mL}^{-1}$ de AA. As leveduras BG-1 e CA-11 produziram destilados com

Tabela 3. Composição química da fração "cabeça" do destilado final dos mostos fermentados com as diferentes leveduras

\begin{tabular}{|c|c|c|c|c|c|c|}
\hline & CA-11 & Y-904 & BG-1 & PE-2 & SA-1 & CAT-1 \\
\hline Teor alcoólico $\left(\% \mathrm{v} \mathrm{v}^{-1} 20^{\circ} \mathrm{C}\right)$ & $76,91^{\mathrm{a}}$ & $77,92^{\mathrm{a}}$ & $75,51^{\mathrm{a}}$ & $77,53^{\mathrm{a}}$ & $76,98^{\mathrm{a}}$ & $77,09^{\mathrm{a}}$ \\
\hline Acidez volátil* & $14,20^{\mathrm{a}}$ & $4,45^{\mathrm{b}}$ & $17,01^{\mathrm{a}}$ & $6,23^{\mathrm{b}}$ & $5,45^{\mathrm{b}}$ & $12,13^{\mathrm{a}}$ \\
\hline Aldeídos* & $99,87^{\mathrm{a}}$ & $53,08^{\mathrm{c}}$ & $67,75^{\mathrm{b}}$ & $47,98^{\mathrm{c}}$ & $51,37^{\mathrm{c}}$ & $73,01^{\mathrm{b}}$ \\
\hline Ésteres* & $54,34^{c}$ & $64,86^{\mathrm{b}}$ & $51,33^{\mathrm{c}}$ & $49,18^{\mathrm{c}}$ & $83,29^{\mathrm{a}}$ & $59,02^{\mathrm{b}}$ \\
\hline Furfural* & $0,03^{\mathrm{a}}$ & $0,02^{\mathrm{a}}$ & $0,04^{\mathrm{a}}$ & $0,04^{\mathrm{a}}$ & $0,01^{\mathrm{a}}$ & $0,03^{\mathrm{a}}$ \\
\hline Álcool n-propílico* & $15,72^{\mathrm{d}}$ & $35,18^{\mathrm{c}}$ & $32,46^{c}$ & $60,63^{\mathrm{a}}$ & $42,73^{\mathrm{b}}$ & $42,29^{\mathrm{b}}$ \\
\hline Álcool iso-butílico* & $46,41^{\mathrm{e}}$ & $191,00^{\mathrm{b}}$ & $72,41^{\mathrm{d}}$ & $250,46^{\mathrm{a}}$ & $200,59^{\mathrm{b}}$ & $148,78^{\mathrm{c}}$ \\
\hline Álcool iso-amílico* & $161,66^{c}$ & $422,65^{\mathrm{a}}$ & $125,14^{c}$ & $280,53^{\mathrm{b}}$ & $373,95^{\mathrm{a}}$ & $223,21^{\mathrm{b}}$ \\
\hline Alcoóis superiores* & $223,79^{c}$ & $648,82^{\mathrm{a}}$ & $198,17^{\mathrm{c}}$ & $591,63^{\mathrm{a}}$ & $617,27^{\mathrm{a}}$ & $414,28^{b}$ \\
\hline Coeficiente de congêneres* & $392,23^{\mathrm{d}}$ & $771,23^{\mathrm{a}}$ & $334,30^{\mathrm{d}}$ & $695,06^{\mathrm{b}}$ & $757,39^{\mathrm{a}}$ & $558,47^{\mathrm{c}}$ \\
\hline Metanol* & $12,69^{\mathrm{b}}$ & $19,35^{\mathrm{a}}$ & $13,91^{\mathrm{b}}$ & $17,77^{\mathrm{ab}}$ & $16,76^{\mathrm{ab}}$ & $13,53^{\mathrm{b}}$ \\
\hline
\end{tabular}

* mg $100 \mathrm{~mL}^{-1}$ de AA. Letras diferentes nas linhas indicam diferença estatística significativa. 
as menores concentrações de alcoóis superiores, 198,17 e 223,79 mg $100 \mathrm{~mL}^{-1}$ de AA, respectivamente.

Os destilados das leveduras Y-904 e SA-1 apresentaram os maio-

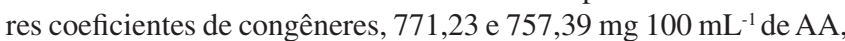
respectivamente. As leveduras BG-1 e CA-11 produziram destilados com os menores coeficientes de congêneres, 334,30 e 392,23 mg 100 $\mathrm{mL}^{-1}$ de AA, respectivamente.

Houve diferença nas concentrações de metanol nas frações "cabeça" dos destilados produzidos com as diferentes leveduras, porém todas ficaram na faixa de 12 a $19 \mathrm{mg} 100 \mathrm{~mL}^{-1}$ de AA.

\section{Fração "coração" (aguardente)}

Em função da dupla destilação, onde a segunda partiu de um low wines com 32,1\% (v/v) de etanol, a concentração alcoólica média das aguardentes produzidas pelas diferentes leveduras foi de $66,1 \%(\mathrm{v} / \mathrm{v})$ (Tabela 4), valor acima do estabelecido pela legislação (máximo de $54 \%$ v/v). ${ }^{3}$ Entretanto, é permitido o procedimento de diluição da aguardente com água potável até a concentração alcoólica desejada para o engarrafamento.

A aguardente produzida pela destilação do mosto fermentado pela levedura BG-1 apresentou a maior acidez volátil $\left(47,14 \mathrm{mg} 100 \mathrm{~mL}^{-1}\right.$ de AA), que é o parâmetro associado ao principal defeito sensorial em bebidas destiladas. A menor acidez volátil $\left(11,62 \mathrm{mg} 100 \mathrm{~mL}^{-1}\right.$ de AA) foi na aguardente da levedura Y-904.

Não se observou diferença significativa na concentração de aldeídos das aguardentes provenientes das fermentações com as diferentes leveduras, indicando que as cepas de Saccharomyces cerevisiae não influenciaram a concentração deste componente na bebida. No entanto, nota-se que o processo de dupla destilação contribuiu para a padronização da concentração de aldeídos entre as aguardentes, já que os low wines obtidos das leveduras testadas mostraram diferença significativa na concentração deste componente.

A maior concentração de ésteres $\left(23,72 \mathrm{mg} 100 \mathrm{~mL}^{-1} \mathrm{de}\right.$ AA) foi na aguardente da levedura SA-1. As aguardentes das leveduras CA11 e PE-2 apresentaram as menores concentrações deste composto, 9,40 e 10,71 mg $100 \mathrm{~mL}^{-1}$ de AA, respectivamente.

As concentrações de ésteres, em acetato de etila, das aguardentes produzidas com as diferentes leveduras ( 9 a $23 \mathrm{mg} 100 \mathrm{~mL}^{-1}$ de AA) são consideradas relativamente baixas. Tal fato se deve à separação na segunda destilação da fração "cabeça", na qual se concentram os compostos de baixo ponto de ebulição, tais como os ésteres, aldeídos e metanol.
A concentração de furfural nas aguardentes variou de 0,11 a 0,25 mg $100 \mathrm{~mL}^{-1}$ de AA.

As aguardentes das leveduras PE-2, SA-1 e CAT-1 apresentaram concentrações de n-propanol entre 30 e $38 \mathrm{mg} 100 \mathrm{~mL}^{-1}$ de AA. As leveduras CA-11 e BG-1 produziram aguardentes com as menores

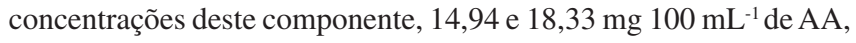
respectivamente.

As aguardentes produzidas pelas leveduras PE-2 e Y-904 apresentaram concentrações de iso-butanol entre 170 e $174 \mathrm{mg} 100 \mathrm{~mL}^{-1} \mathrm{de}$ AA. A aguardente com a menor concentração deste álcool superior foi produzida pela levedura CA-11 (35,47 mg $100 \mathrm{~mL}^{-1}$ de AA).

A levedura Y-904 originou a aguardente com a maior concentração de álcool iso-amílico (415,78 mg $100 \mathrm{~mL}^{-1}$ de AA). A aguardente da levedura BG-1 apresentou a menor concentração deste composto (75,95 mg $100 \mathrm{~mL}^{-1}$ de AA).

A Y-904 foi também a levedura que produziu a aguardente com maior concentração de alcoóis superiores $\left(616,02 \mathrm{mg} 100 \mathrm{~mL}^{-1} \mathrm{de}\right.$ AA). A aguardente com a menor concentração de alcoóis superiores foi obtida da levedura BG-1 (146,74 mg $100 \mathrm{~mL}^{-1}$ de AA), não diferindo da levedura CA-11 (195,72 mg $100 \mathrm{~mL}^{-1}$ de AA).

As aguardentes provenientes das fermentações com as leveduras Y-904, PE-2 e SA-1 apresentaram concentração de alcoóis superiores acima do limite máximo estabelecido pela legislação (360 mg 100 $\mathrm{mL}^{-1}$ de AA). ${ }^{3}$

Os maiores coeficientes de congêneres foram observados nas aguardentes das leveduras Y-904 (654,59 mg $100 \mathrm{~mL}^{-1}$ de AA) e SA-1 (596,75 mg $100 \mathrm{~mL}^{-1}$ de AA). As leveduras BG-1 e CA-11 produziram aguardentes com as menores quantidade de congêneres, 225,65 e 247,51 mg $100 \mathrm{~mL}^{-1}$ de AA, respectivamente. Os valores nas aguardentes produzidas pelas leveduras CAT-1 e PE-2 foram 414,67 e 477,37 mg $100 \mathrm{~mL}^{-1}$ de AA, respectivamente.

Apesar de ter havido diferenças entre as aguardentes, todas apre-

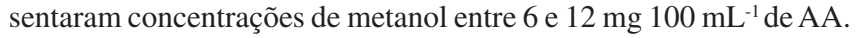

\section{Fração "cauda"}

O teor alcoólico médio da fração "cauda" da segunda destilação foi de 28,0\% (v/v) (Tabela 5).

A fração "cauda" da destilação do mosto fermentado pela levedura BG-1 apresentou a maior acidez volátil, 183,07 mg $100 \mathrm{~mL}^{-1} \mathrm{de}$ AA. O destilado da levedura SA-1 apresentou a menor acidez volátil, $100,56 \mathrm{mg} 100 \mathrm{~mL}^{-1}$ de AA.

Não foram detectados aldeídos e ésteres nos destilados das

Tabela 4. Composição química da aguardente (fração "coração") do destilado final dos mostos fermentados com as diferentes leveduras

\begin{tabular}{|c|c|c|c|c|c|c|}
\hline & CA-11 & Y-904 & BG-1 & PE-2 & SA-1 & CAT-1 \\
\hline Teor alcoólico $\left(\% \mathrm{v} \mathrm{v}^{-1} 20^{\circ} \mathrm{C}\right)$ & $65,81^{\mathrm{a}}$ & $67,15^{\mathrm{a}}$ & $64,89^{\mathrm{a}}$ & $66,67^{\mathrm{a}}$ & $66,12^{\mathrm{a}}$ & $66,17^{\mathrm{a}}$ \\
\hline Acidez volátil** & $23,67^{\mathrm{b}}$ & $11,62^{\mathrm{c}}$ & $47,14^{\mathrm{a}}$ & $19,98^{\mathrm{b}}$ & $14,83^{\mathrm{bc}}$ & $22,81^{\mathrm{b}}$ \\
\hline Aldeídos* & $18,52^{\mathrm{a}}$ & $14,32^{\mathrm{a}}$ & $16,10^{\mathrm{a}}$ & $15,31^{\mathrm{a}}$ & $15,78^{\mathrm{a}}$ & $16,89^{\mathrm{a}}$ \\
\hline Ésteres* & $9,40^{\mathrm{c}}$ & $12,47^{\mathrm{bc}}$ & $15,49^{\mathrm{b}}$ & $10,71^{\mathrm{c}}$ & $23,72^{\mathrm{a}}$ & $15,74^{\mathrm{b}}$ \\
\hline Furfural* & $0,20^{\mathrm{a}}$ & $0,16^{\mathrm{b}}$ & $0,18^{\mathrm{b}}$ & $0,21^{\mathrm{ab}}$ & $0,11^{\mathrm{c}}$ & $0,25^{\mathrm{a}}$ \\
\hline Álcool n-propílico* & $14,94^{\mathrm{c}}$ & $25,65^{\mathrm{b}}$ & $18,33^{\mathrm{c}}$ & $38,54^{\mathrm{a}}$ & $31,15^{\mathrm{ab}}$ & $30,31^{\mathrm{ab}}$ \\
\hline Álcool iso-butílico* & $35,47^{\mathrm{e}}$ & $174,59^{\mathrm{a}}$ & $52,45^{\mathrm{d}}$ & $170,24^{\mathrm{a}}$ & $148,66^{\mathrm{b}}$ & $118,26^{\circ}$ \\
\hline Álcool iso-amílico* & $145,31^{\mathrm{d}}$ & $415,78^{\mathrm{a}}$ & $75,95^{\mathrm{e}}$ & $222,38^{\mathrm{c}}$ & $362,50^{\mathrm{b}}$ & $210,41^{\circ}$ \\
\hline Alcoóis superiores* & $195,72^{\mathrm{e}}$ & $616,02^{\mathrm{a}}$ & $146,74^{\mathrm{e}}$ & $431,16^{\mathrm{c}}$ & $542,31^{\mathrm{b}}$ & 358,98 \\
\hline Coeficiente de congêneres* & $247,51^{\mathrm{c}}$ & $654,59^{\mathrm{a}}$ & $225,65^{\mathrm{c}}$ & $477,37^{\mathrm{b}}$ & $596,75^{\mathrm{a}}$ & $414,67^{\mathrm{b}}$ \\
\hline Metanol* $^{*}$ & $6,66^{\mathrm{c}}$ & $12,34^{\mathrm{a}}$ & $7,14^{\mathrm{bc}}$ & $9,18^{\mathrm{b}}$ & $8,74^{\mathrm{b}}$ & $6,85^{c}$ \\
\hline
\end{tabular}

* mg $100 \mathrm{~mL}^{-1}$ de AA. Letras diferentes nas linhas indicam diferença estatística significativa. 
Tabela 5. Composição química da fração "cauda" do destilado final dos mostos fermentados com as diferentes leveduras

\begin{tabular}{|c|c|c|c|c|c|c|}
\hline & CA-11 & Y-904 & BG-1 & PE-2 & SA-1 & CAT-1 \\
\hline Teor alcoólico $\left(\% \mathrm{v} \mathrm{v}^{-1} 20^{\circ} \mathrm{C}\right)$ & $28,20^{\mathrm{a}}$ & $28,25^{\mathrm{a}}$ & $26,14^{\mathrm{a}}$ & $27,80^{\mathrm{a}}$ & $28,54^{\mathrm{a}}$ & $28,98^{\mathrm{a}}$ \\
\hline Acidez volátil* & $124,51^{\mathrm{c}}$ & $130,45^{\mathrm{c}}$ & $183,07^{\mathrm{a}}$ & $137,75^{\mathrm{c}}$ & $100,56^{\mathrm{d}}$ & $162,62^{\mathrm{b}}$ \\
\hline Aldeídos* & nd & nd & nd & nd & nd & nd \\
\hline Ésteres* & nd & nd & nd & nd & nd & nd \\
\hline Furfural* & $0,36^{\mathrm{c}}$ & $0,88^{\mathrm{a}}$ & $0,61^{\mathrm{b}}$ & $0,71^{\mathrm{b}}$ & $0,30^{\mathrm{c}}$ & $0,45^{\mathrm{c}}$ \\
\hline Álcool n-propílico* & $14,03^{\mathrm{a}}$ & $0,29^{\mathrm{b}}$ & $2,31^{\mathrm{b}}$ & $3,36^{\mathrm{b}}$ & $2,08^{\mathrm{b}}$ & $1,03^{\mathrm{b}}$ \\
\hline Álcool iso-butílico* & $9,23^{\mathrm{b}}$ & $11,12^{\mathrm{b}}$ & $8,55^{\mathrm{b}}$ & $18,17^{\mathrm{a}}$ & $16,50^{\mathrm{a}}$ & $8,29^{\mathrm{b}}$ \\
\hline Álcool iso-amílico* & $34,64^{\mathrm{b}}$ & $37,85^{\mathrm{b}}$ & $20,26^{\mathrm{c}}$ & $33,48^{\mathrm{b}}$ & $48,08^{\mathrm{a}}$ & $24,38^{\mathrm{c}}$ \\
\hline Alcoóis superiores* & $57,90^{\mathrm{a}}$ & $49,26^{\mathrm{ab}}$ & $31,13^{\mathrm{b}}$ & $57,01^{\mathrm{a}}$ & $66,66^{\mathrm{a}}$ & $33,71^{\mathrm{b}}$ \\
\hline Coeficiente de congêneres* & $182,77^{\mathrm{a}}$ & $180,59^{\mathrm{a}}$ & $214,81^{\mathrm{a}}$ & $195,47^{\mathrm{a}}$ & $167,52^{\mathrm{a}}$ & $196,78^{\mathrm{a}}$ \\
\hline Metanol* & $1,62^{\mathrm{a}}$ & $3,54^{\mathrm{a}}$ & $2,02^{\mathrm{a}}$ & $3,33^{\mathrm{a}}$ & $2,81^{\mathrm{a}}$ & $1,37^{\mathrm{a}}$ \\
\hline
\end{tabular}

* mg $100 \mathrm{~mL}^{-1}$ de AA. nd = não detectado. Aldeídos $(\mathrm{LD}=0,23, \mathrm{LQ}=0,77)$. Ésteres $(\mathrm{LD}=0,19, \mathrm{LQ}=0,63)$. LD = limite de detecção, $\mathrm{LQ}=$ limite de quantificação, ambos em mg $100 \mathrm{~mL}^{-1}$ de AA. Letras diferentes nas linhas indicam diferença estatística significativa.

diferentes cepas de leveduras. A concentração de furfural variou de 0,30 a $0,88 \mathrm{mg} 100 \mathrm{~mL}^{-1} \mathrm{de}$ AA.

O destilado da levedura CA-11 apresentou a maior concentração de n-propanol (14,03 mg $100 \mathrm{~mL}^{-1}$ de AA). Para as demais leveduras, esta concentração ficou entre 0,29 e $3,36 \mathrm{mg} 100 \mathrm{~mL}^{-1}$ de AA.

Os destilados das leveduras SA-1 e PE-2 apresentaram as maiores concentrações de iso-butanol, 16,50 e 18,17 mg $100 \mathrm{~mL}^{-1}$ de AA, respectivamente. Para os demais destilados, a concentração deste álcool superior foi de 8,29 a 11,12 mg $100 \mathrm{~mL}^{-1}$ de AA.

A fração "cauda" da levedura SA-1 apresentou a maior concentração de álcool iso-amílico (48,08 mg $100 \mathrm{~mL}^{-1}$ de AA). A menor concentração deste componente foi observada para a levedura BG-1 (20,26 mg $100 \mathrm{~mL}^{-1}$ de AA), não diferindo da levedura CAT-1, que apresentou 24,38 mg $100 \mathrm{~mL}^{-1}$ de AA de álcool iso-amílico.

Os destilados das leveduras Y-904, PE-2, CA-11 e SA-1 apresentaram concentrações de alcoóis superiores entre 57 e 66 mg 100 $\mathrm{mL}^{-1}$ de AA. As leveduras BG-1 e CAT-1 produziram destilados com as menores concentrações destes alcoóis, 31,13 e $33,71 \mathrm{mg} 100 \mathrm{~mL}^{-1}$ de AA, respectivamente.

Não foram observadas diferenças nos coeficientes de congêneres e nas concentrações de metanol dos destilados provenientes das diferentes leveduras.

Observou-se influência da cepa de levedura na composição química dos destilados e das aguardentes produzidas por dupla destilação.

Alves et al. ${ }^{23}$ observaram que a presença e a concentração de compostos voláteis em mosto fermentado de lichia foi dependente da cepa de levedura utilizada para as fermentações. A bebida fermentada com a cepa UFLA CA 1183 apresentou maior complexidade de compostos aromáticos que as bebidas produzidas pelas cepas UFLA CA 116 e UFLA CA 1174 e pela fermentação espontânea.

Vicente et al. $^{2}$ isolaram cepas de levedura Saccharomyces cerevisiae de dornas de fermentação de processos industriais de produção de cachaça e as caracterizaram quanto a parâmetros fermentativos e produção de compostos químicos aromáticos. As cepas isoladas, apesar de apresentarem perfis fermentativos similares, produziram diferentes níveis de compostos aromáticos importantes para as propriedades sensoriais da bebida.

Soares et al. ${ }^{15}$ quantificaram os compostos metabólicos produzidos durante a fermentação de caldo de cana por diferentes cepas de leveduras Saccharomyces cerevisiae (UFLA CA116, UFLA CA1183, UFLA CA1162, SA-1, PE-2, BG-1, VR-1 e CAT-1). De modo geral, as cepas de Saccharomyces cerevisiae apresentaram diferenças na produção de metabólitos secundários durante a fermentação do caldo de cana. As autoras observaram que a cepa UFLA CA116 foi a que produziu maior concentração de acetato de etila e a cepa PE-2 produziu a maior concentração de acetaldeído. Concluíram que a melhor cepa para a produção de cachaça foi a UFLA CA116, por não ter produzido propanol, ter apresentado a maior formação de 1,3-butanediol e a menor formação de acetaldeído na fermentação.

Analisando cachaças obtidas pela destilação simples de caldos de cana fermentados pela levedura CA-11, Duarte et al. ${ }^{24}$ obtiveram acidez volátil de 28,72; alcoóis superiores em concentração de 231,52; aldeídos de 13,13; ésteres de 56,70; teor de congêneres de 330,09 e metanol de 5,0, todos expressos em mg $100 \mathrm{~mL}^{-1}$ de AA. Os mesmos autores também analisaram as frações "cabeça" e "cauda" dos destilados e observaram que os componentes ésteres, aldeídos e alcoóis superiores foram encontrados em maior concentração na fração "cabeça" do que na fração "cauda". Estes resultados estão em conformidade com os obtidos no presente trabalho para esta mesma levedura, levando em consideração que na presente pesquisa a aguardente foi obtida por dupla destilação.

As concentrações (mg $100 \mathrm{~mL}^{-1}$ de AA) de compostos voláteis em cachaças produzidas pela destilação de caldo fermentado por 4 diferentes cepas de Saccharomyces cerevisiae (UFMGA 1240, 1799, 1207 e 905) variaram de 12,9 a 23,4 para aldeído acético; 9,7 a 32,3 para acetato de etila; 110,7 a 450,4 para alcoóis superiores; 12,1 a 148,8 para acidez volátil e 308,3 a 491,2 para teor de congêneres. ${ }^{11}$

Oliveira et al. ${ }^{25}$ observaram variação de, no máximo, $50 \%$ nas concentrações de acetaldeído, acetato de etila, propanol, isobutanol, álcool isoamílico, ácido acético e glicerol em mostos fermentados provenientes de fermentações para produção de cachaça, realizadas por 24 diferentes cepas de levedura Saccharomyces cerevisiae.

Campos et al. ${ }^{26}$ não observaram diferença qualitativa nos compostos químicos de cachaças produzidas por 3 cepas selecionadas de Saccharomyces cerevisiae (UFLA CA 116, UFLA CA 1162 e UFLA CA 1183), porém houve diferença quantitativa destes compostos nas cachaças. As cepas UFLA CA 1162 e UFLA CA 116 foram consideradas as mais indicadas para a produção de cachaça de alambique.

Oliveira et al. ${ }^{27}$ analisaram cachaças monodestiladas produzidas por 6 diferentes cepas de Saccharomyces cerevisiae e obtiveram concentrações (mg 100 $\mathrm{mL}^{-1}$ de AA) de acetaldeído variando de 7,4 a 18,2; acetato de etila de 9,8 a 36,5 ; alcoóis superiores de 241,6 a 351,6; acidez volátil de 28,4 a 121,4 e teor de congêneres de 287,1 a 527,7. Apesar das cachaças produzidas pelas diferentes leveduras terem apresentado variações na concentração dos principais compostos voláteis, não foi observada diferença significativa nas suas 
características sensoriais de aroma, sabor e impressão global.

Cole e Noble citam que o aroma e o sabor em sistemas complexos, como bebidas destiladas, não podem ser inferidos a partir de análises químicas isoladas, pois as percepções destes atributos resultam da combinação de vários componentes. ${ }^{28}$

No entanto, apesar de testes sensoriais com painéis de provadores serem essenciais para a confirmação da aceitabilidade de bebidas, alguns compostos podem ser considerados indicadores da qualidade sensorial de bebidas alcoólicas. Silva et al. ${ }^{29}$ observaram correlação positiva entre a concentração de propanol de cachaças e sua aceitação sensorial quanto a sabor e aroma. Oliveira et al..$^{25}$ correlacionaram a concentração de compostos voláteis com os resultados da análise sensorial de cachaças e também observaram que o propanol influenciou positivamente os atributos sabor e impressão global. No entanto, Boza e Horii citam que o propanol influiu negativamente na qualidade sensorial de cachaças. ${ }^{20}$ Almeida e Barreto citam que a ocorrência de teores elevados de propanol (55 a $65 \mathrm{mg} 100 \mathrm{~mL}^{-1}$ de AA) influenciou negativamente a qualidade sensorial de cachaças. ${ }^{30}$ No presente trabalho, todas as cachaças apresentaram concentração de propanol

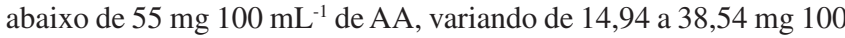
$\mathrm{mL}^{-1}$ de AA, tendo apresentado, portanto, características favoráveis à qualidade sensorial da bebida quanto à concentração de propanol.

Das leveduras testadas neste trabalho, a acidez volátil da aguardente produzida a partir da fermentação do mosto pela cepa BG-1 (47,14 mg $100 \mathrm{~mL}^{-1}$ de AA), apesar de estar dentro dos parâmetros legais (máximo $150 \mathrm{mg} 100 \mathrm{~mL}^{-1}$ de AA), apresentou acidez volátil bem superior à das aguardentes produzidas a partir das outras cepas, as quais ficaram entre $11 \mathrm{e} 23 \mathrm{mg} 100 \mathrm{~mL}^{-1}$ de AA. Silva et al. ${ }^{29}$ observaram correlação inversa entre a acidez volátil e a aceitação sensorial de cachaças.

Comparando as leveduras, a aguardente produzida pela destilação do mosto fermentado pela levedura BG-1 apresentou a maior acidez volátil (47,14 mg $100 \mathrm{~mL}^{-1}$ de AA), que é o parâmetro associado ao principal defeito sensorial em bebidas destiladas. A aguardente oriunda da fermentação com a levedura Y-904 apresentou a menor acidez volátil (11,62 mg $100 \mathrm{~mL}^{-1}$ de AA).

Singer cita que quanto maior a relação entre os compostos propanol:isobutanol e álcool isoamílico:isobutanol, melhor a qualidade da bebida. ${ }^{31}$ No presente trabalho, a aguardente produzida pela destilação dos mostos fermentados pela levedura CA-11 foi a que apresentou as mais altas relações propanol:isobutanol e álcool isoamílico:isobutanol, 0,42 e 4,10 mg $100 \mathrm{~mL}^{-1}$ de AA, respectivamente. Assim sendo, a levedura CA-11 pode ser considerada, dentre as cepas testadas, a mais indicada para a produção de aguardentes com características sensoriais diferenciadas, capazes de propiciar a conquista de um espaço no mercado para consumidores mais exigentes.

Investigando o desempenho fermentativo das cepas PE-2, CAT1, VR-1 e BG-1 da levedura Saccharomyces cerevisiae, inoculadas em mostos para a produção de whisky, Berbert de Amorim Neto et $a l .{ }^{32}$ observaram que a cepa CAT- 1 obteve performance fermentativa semelhante à de uma levedura tradicionalmente utilizada na Escócia para a fermentação dos mostos de cereais, a M Type. Os autores observaram ainda que o destilado obtido pela destilação do mosto fermentado pela levedura CAT-1 apresentou perfis de aroma e sabor semelhantes aos do destilado obtido pela destilação do mosto fermentado pela levedura $M$ Type.

Os aldeídos, ésteres e metanol apresentaram comportamento característico de componentes de "cabeça", pois se volatilizaram majoritariamente nas primeiras frações do destilado da segunda destilação. Os alcoóis superiores (n-propanol, iso-butanol e iso-amílico) volatilizaram-se principalmente nas frações "cabeça" e "coração" do destilado da segunda destilação. A acidez volátil e o furfural apresentaram comportamento típico de componentes de "cauda", pois se volatilizaram principalmente nas frações finais do destilado da segunda destilação (Tabela 6).

Estes resultados estão de acordo com os citados por Leauté sobre a cinética de volatilização de componentes secundários durante o processo de destilação para produção de cognac. O autor cita acetaldeído, metanol e acetato de etila como componentes que, por terem ponto de ebulição relativamente baixo e serem solúveis em etanol, se volatilizam prioritariamente no início do processo de destilação, sendo suas concentrações relativamente maiores nas primeiras frações do destilado, isto é, na fração "cabeça". Os alcoóis superiores propanol, iso-butanol e iso-amílico são classificados pelo autor como componentes que, por serem solúveis em álcool e completa ou parcialmente solúveis em água, se concentram nas frações "cabeça" e "coração" do destilado. O ácido acético e o furfural, por terem ponto de ebulição maior que o da água e serem muito solúveis nela, volatilizam-se preferencialmente ao final do processo de destilação, acumulando-se na fração "cauda" do destilado. ${ }^{33}$

Comparativamente aos low wines, a dupla destilação proporcionou diminuição da acidez volátil e da concentração de metanol do destilado final. Bizelli et al. ${ }^{34}$ também observaram que a dupla

Tabela 6. Composição química média do low wines e das frações "cabeça", "coração" (aguardente) e "cauda" do destilado final dos mostos fermentados com as diferentes leveduras

\begin{tabular}{|c|c|c|c|c|}
\hline & Low wines & Fração "cabeça" & Fração "coração" (Aguardente) & Fração "cauda" \\
\hline Teor alcoólico $\left(\% \mathrm{v} \mathrm{v}^{-1} 20^{\circ} \mathrm{C}\right)$ & $32,11^{\mathrm{c}}$ & $76,99^{\mathrm{a}}$ & $66,14^{\mathrm{b}}$ & $27,99^{\mathrm{c}}$ \\
\hline Acidez volátil* & $175,43^{\mathrm{a}}$ & $9,91^{\mathrm{c}}$ & $23,34^{\mathrm{b}}$ & $139,83^{\mathrm{a}}$ \\
\hline Aldeídos* & $17,88^{\mathrm{b}}$ & $65,51^{\mathrm{a}}$ & $16,15^{\mathrm{b}}$ & nd \\
\hline Ésteres* & $19,21^{\mathrm{b}}$ & $60,34^{\mathrm{a}}$ & $14,59^{\mathrm{b}}$ & nd \\
\hline Furfural* & $0,14^{\mathrm{b}}$ & $0,03^{\mathrm{c}}$ & $0,19^{\mathrm{b}}$ & $0,55^{\mathrm{a}}$ \\
\hline Álcool n-propílico* & $27,08^{\mathrm{a}}$ & $38,17^{\mathrm{a}}$ & $26,49^{a}$ & $3,85^{\mathrm{b}}$ \\
\hline Álcool iso-butílico* & $108,02^{\mathrm{a}}$ & $151,61^{\mathrm{a}}$ & $116,61^{\mathrm{a}}$ & $11,98^{\mathrm{b}}$ \\
\hline Álcool iso-amílico* & $204,75^{\mathrm{a}}$ & $264,52^{\mathrm{a}}$ & $238,72^{\mathrm{a}}$ & $33,12^{\mathrm{b}}$ \\
\hline Alcoóis superiores* & $339,85^{\mathrm{a}}$ & $448,99^{\mathrm{a}}$ & $381,82^{\mathrm{a}}$ & $49,28^{\mathrm{b}}$ \\
\hline Coeficiente de congêneres* & $552,51^{\mathrm{a}}$ & $584,78^{\mathrm{a}}$ & $436,09^{\mathrm{a}}$ & $189,66^{\mathrm{b}}$ \\
\hline Metanol* & $17,24^{\mathrm{a}}$ & $15,67^{\mathrm{a}}$ & $8,49^{\mathrm{b}}$ & $2,45^{\mathrm{c}}$ \\
\hline
\end{tabular}

* mg $100 \mathrm{~mL}^{-1}$ de AA. nd = não detectado. Aldeídos $(\mathrm{LD}=0,23, \mathrm{LQ}=0,77)$. Ésteres $(\mathrm{LD}=0,19, \mathrm{LQ}=0,63) . \mathrm{LD}=$ limite de detecção, $\mathrm{LQ}=$ limite de quantificação, ambos em mg $100 \mathrm{~mL}^{-1}$ de AA. Letras diferentes nas linhas indicam diferença estatística significativa. 
destilação influenciou positivamente as características físico-químicas da aguardente de cana-de-açúcar, pois reduziu a acidez volátil e as concentrações de cobre e metanol da bebida. Os autores citaram que os componentes que conferem acidez ao destilado apresentam baixa volatilidade em vinhos com alto teor alcoólico, volatilizando-se apenas nas frações finais da destilação, isto é, na fração "cauda". Boza e Horii também verificaram que a dupla destilação reduziu o teor de acidez da cachaça, sendo favorável à melhoria do flavor do produto e à aceitação pelo consumidor..$^{20}$

Segundo Franco, a dupla destilação permite uma concentração maior de etanol no destilado, eliminando parte da água e de algumas substâncias consideradas contaminantes, como aldeídos, metanol, ácido acético, cobre e carbamato de etila, e melhorando a qualidade sensorial da bebida. ${ }^{35}$

\section{CONCLUSÕES}

As aguardentes duplamente destiladas provenientes das fermentações com as diferentes cepas de levedura Saccharomyces cerevisiae apresentaram composições químicas distintas.

As aguardentes provenientes das fermentações com as leveduras CA-11, BG-1 e CAT-1 apresentaram composição química dentro dos limites estabelecidos pela legislação brasileira.

Dentre as cepas de levedura estudadas, a aguardente produzida pela fermentação com a cepa BG-1 apresentou a maior acidez volátil, que é parâmetro associado a defeito sensorial em bebidas destiladas.

A cepa CA-11 foi a que produziu a aguardente com a melhor composição química relacionada à qualidade sensorial.

\section{REFERÊNCIAS}

1. Tfouni, S. A. V.; Machado, R. M. D.; Camargo, M. C. R.; Vitorino, S. H. P.; Vicente, E.; Toledo, M. C. F.; World J. Microbiol. Biotechnol. 2007, 24, 2705 .

2. Vicente, M. A.; Fietto, L. G.; Castro, I. M.; Coutrim, M. X.; Brandão, R. L.; Int. J. Food Microbiol. 2006, 108, 51.

3. Brasil, Ministério da Agricultura Pecuária e Abastecimento; Instrução Normativa $n^{\circ} 13$, de 29/6/2005, Diário Oficial da União, seção 1, p. 3-4, 30/6/2005.

4. Cardoso, M. G.; Produção de aguardente de cana-de-açúcar, Ed. UFLA: Lavras, 2006.

5. Odello, L.; Braceschi, G. P.; Seixas, F. R. F.; Silva, A. A.; Galinaro, C. A.; Franco, D. W.; Quim. Nova 2009, 32, 1844.

6. Nascimento, E. S. P.; Cardoso, D. R.; Franco, D. W.; Quim. Nova 2009, 32, 2327.

7. Silva-Filho, E. A.; Santos, S. K. B.; Resende, A. M.; Morais, J. O. F.; Morais Jr., M. A.; Simões, D. A.; J. Microbiol. 2001, 88, 13.

8. Klosowski, G.; Czuprynski, B.; J. Food Eng. 2006, 72, 242.

9. Janzantti, N. S.; Tese de Doutorado, Universidade Estadual de Campinas, Brasil, 2004.

10. Cavalcanti, A. F.; Rota, M. B.; Janzantti, N. S.; Faria, J. B.; Resumos do $21^{a}$ Congresso Brasileiro de Ciência e Tecnologia de Alimentos, Belo Horizonte, Brasil, 2008.
11. Giudici, P.; Zambonelli, C.; Kunkee, R. E.; Am. J. Enol. Vitic. 1993. 44 , 17.

12. Basso, L. C.; Amorim, H. V.; Oliveira, A. J.; Lopes, M. L.; FEMS Yeast Res. 2008, 8, 1163.

13. Campos, C. R.; Silva, C. F.; Dias, D. R.; Basso, L. C.; Amorim, H. V.; Schwan, R. F; J. Appl. Microbiol. 2009, 107, 9.

14. Schwan, R. F.; Mendonça, A. T.; Silva Júnior, J. J.; Rodrigues, V.; Wheals, A. E.; J. Microbiol. 2001, 79, 89.

15. Soares, T. L.; Silva, C. F.; Schwan, R. F.; Ciência Tecn. Alim. 2011, 31, 184.

16. Bernardi, T. L.; Pereira, G. V. M.; Cardoso, P. G.; Dias, E. S.; Schwan, R. F.; World J. Microbiol. Biotechnol. 2008, 24, 2705.

17. Campos, C. R.; Silva, D. R.; Basso, L. C.; Amorim, H. V.; Schwan, R. F.; J. Appl Microbiol. 2010, 108, 1871.

18. Piggott, J. R.; Conner, J. M. Em Fermented Beverage Production; Lea, A. G. H.; Piggott, J. R., eds.; Klumer Academic/Plenum Publishers: New York, 2003, chap. 11.

19. Brasil, Ministério da Agricultura Pecuária e Abastecimento; Instrução Normativa ${ }^{\circ}$ 24, de 8/9/2005, Diário Oficial da União, seção 1, p. 2, 09/9/2005

20. Boza, Y. E. A. G.; Horii, J.; Ciência Tecn. Alim. 1998, 18, 391

21. SAS; Statistical Analysis System Institute; Cary, USA, 1996.

22. Pimentel-Gomes, F.; Garcia, C. H.; Estatística aplicada a experimentos agronômicos e florestais: exposição com exemplos e orientações para uso de aplicativos, FEALQ: Piracicaba, 2002.

23. Alves, J. A. ; Lima, L. C. O. ; Dias, D. R. ; Nunes, C. A. ; Schwan, R.F. ; Int. J. Food Sci. Technol. 2010, 45, 2358.

24. Duarte, W. F. ; Sousa, M. V. F. ; Schwan, R. F. ; J. Food Sci. 2011, 78, 307.

25. Oliveira, S. E.; Cardello, H. M. A. B.; Jeronimo, E. M.; Souza, E. L. R.; Serra, G. E.; World J. Microbiol. Biotechnol. 2005, 21, 707.

26. Campos, C. R.; Silva, D. R.; Basso, L. C.; Amorim, H. V.; Schwan, R. F.; J. Appl. Microbiol. 2009, 107, 1.

27. Oliveira, S. E.; Rosa, C. A.; Morgano, M. A.; Serra, G. E.; World J. Microbiol. Biotechnol. 2005, 21, 1569.

28. Cole, V. C.; Noble, A. C. Em Fermented Beverage Production; Lea, A. G. H.; Piggott, J. R., eds.; Blackie Academic and Professional: London, 1995, chap. 7.

29. Silva, C. L. C.; Rosa, C. A.; Maia, A. B. R. A.; Oliveira, E. S.; B. Ceppa 2006, $24,422$.

30. Almeida, M. E. W.; Barreto, H. H. C.; Revista Inst. Adolfo Lutz 1971, 31, 117.

31. Singer, D. D.; Analyst 91 1966, 127.

32. Berbert de Amorim Neto, H.; Yohannan, B. K.; Bringhurst, T. A.; Brosnan, J. M.; Pearson, S. Y.; Walker, J. W.; Walker, G. M.; J. Inst. Brew. 2009, 115, 207.

33. Léauté, R.; Am. J. Enol. Vitic. 1990, 41, 103.

34. Bizelli, L. C.; Ribeiro, C. A. F.; Novaes, F. V.; Sci. Agric. 2000, 57, 627.

35. Franco, A. C.; Dissertação de Mestrado, Universidade Estadual Paulista "Júlio de Mesquita Filho", Brasil, 2008. 